\title{
Avrupa Birliği Anlaşması-Değişiklik Prosedürü
}

\author{
Prof. Dr. Füsun Arsava \\ A.ü. Siyasal Bilgiler Fakültesi \\ Ögretim Üyesi
}

\section{Özet}

Avrupa Toplulukları klasik uluslararası anlaşmalardan farklı olarak diplomatik yoldan değiştirilemez. Üye devletler ve Topluluk organlarının işbirliği yapmasın öngören değişiklik mekanizması Maastricht anlaşmasının $N$ maddesinde düzenlenmiştir. Makalede söz konusu değişiklik prosedürüne ışık tutulmaktadır.

\section{Treaty of European Union - Amendment Procedure}

\section{Abstract}

The European Communities, apart from the classical international organizations, have dynamic structural characteristics. This dynamism is partiaally created by the transformation process witnessed in the treaties establishing the European Communities. The original article 236 of the Treaty of Rome and article "N" of the Maastricht Treaty regulates the ammendment procedure of the treaties establishing the Communities. This study clarifies procedure concerning the functioning of article "N". 


\section{Avrupa Birliği Anlaşması - Değişiklik Prosedürü}

Avrupa Birliği Anlaşması (Maastricht Anlaşması) Madde N (Amsterdam Anlaşması md.48) Birliğin istinat ettiği anlaşmaların değiştirilmesi prosedürünü belirlemektedir. Amsterdam Anlaşması hem AB Anlaşmasını hem de AT Anlaşmasını değiştiren bir metindir. Söz konusu konuları yeni maddelerle düzenlemiştir. Anlaşma, Ekim 1997'de imzalanmış ancak henüz onaylanmaması nedeniyle yürürlüğe girmemiştir. Anlaşmalar kavramına AT, AAET, AKÇT ve AB Anlaşması ile ek ve protokolleri dahildir. AB Anlaşmasının madde $N, 1$.fikra muvacehesinde AET Anlaşmasının 236.maddesi, AAET Anlaşmasının 204. maddesi ve AKÇT Anlaşmasııın 96.maddesi anlaşma değişikliğine ilişkin hükümler olarak Amsterdam Anlaşması tarafından değiştirilmiştir. Birlik Anlaşmasında yer alan anlaşma değişikliğine ilişkin hüküm primer hukuk normu olarak evvelemirde Topluluk anlaşmaları için hüküm ve sonuç doğurmaktadır. Madde N (AB Anlaşması) Topluluk anlaşmalarının, Birlik anlaşmasının bu değişikliği yapması nispetinde değişeceğini öngörmektedir. Bu durum, Topluluk anlaşmasinin açı, lafzi değişikliğini öngören AB Anlaşmasının II-IV. başlıklarından öteye, Birlik Anlaşması tarafından açıkça kabul edilen ancak primer hukuka lafzen girmemiş zımni anlaşma değişiklikleri için de geçerlidir. Buna, Maastricht Anlaşmasının $N$ maddesinin kendisi de dahildir. AT primer hukukunda anlaşma değişikliği konusunda öngörülen hüküm, ayn koşullarla, değişikliğe uğrayabilir. Anlaşma değişikliği prosedürü supranasyonal karakterli birinci sütun ve intergouvernemental karakterli ortak dış ve güvenlik politikası ve adalet ve iç işlerinde işbirliği sütunlarında oldukça kompleks bir işlemle gerçekleşmektedir. Ortak dış ve güvenlik politikası ve adalet ve iç işlerinde işbirliği Amsterdam Anlaşmasına göre de intergouvermental karakterli düzenlenmiştir. Bu politik alanlara ilişkin yetkiler yüksek bir egemen güce devredilmemiştir. Maastricht Anlaşmasının adalet ve içişlerinde işbirliği çerçevesinde üye devlet yetkililerinin koordine edilmesini öngören md.K.9'u, AB/Amsterdam Anlaşmasının md.42 ile teyit edilmektedir.

Amsterdam Anlaşması Avrupa Konseyi tarafından Maastricht Anlaşması md.N fikra 2'de öngörülen düzenlemenin bir sonucu olarak gerçekleştirilen 
hükümetler arası konferansın bir sonucu olarak Haziran 1997'de kararlaştırılmış ve şeklen Ekim 1997'de imzalanmıştır. Bu anlaşma, ortak dıs politika ve güvenlik ve adalet ve içişlerinde işbirliği alanlarının intergouvernemental karakterine ve $A B$ 'nin temel yapısına ilişkin prensiplere de herhangi bir değişiklik getirmemiştir. Ancak, Topluluğa adalet ve içişlerine ilişkin alanlarda önemli üye devlet yetkileri devredilmiştir (Amsterdam Anlaşması ile AT Anlaşmasına yeni bir IV. başlık eklenmiştir: "Vize, iltica, göç ve kişilerin serbest dolaşımına ilişkin diğer politikalar"). AT Anlaşması/Amsterdam 61.madde ve devamında adalet ve iş işlerinde işbirliği alanlarında Birlik hukuku oluşturulmasın kabul etmiştir (AB Anlaşması/ Amsterdam md.2,4). AT Anlaşmasının yeni başlıklarında intergouvernemental karakterli adalet ve içişlerine ilişkin birçok alan Topluluğa maledilmiştir. Yeni başlıkta yer alan hükümler ve bu hükümlere istinat eden sekunder hukuk, İngiltere, İrlanda ve Danimarka'da, bu devletler ek protokollerde yer alan özel durumlarından vazgeçmedikleri nisbette, geçerli olmayacaktır. $\mathrm{AB}$ Anlaşmasının yeni başlıkları, bu şekilde $A B$ Anlaşması/Amsterdam 43.madde ve devamında yer alan esneklik prensibi ısığında genel düzenlemenin bir yansıması olarak farklı huzlarda Avrupa yaratma konseptinin bir ifadesidir. Bunun ötesinde yeni başlıkları AT Anlaşmasının diğer hükümlerinden ayıran özellik, üye devletlerin adalet ve içişleri alanını Topluluğa maletme bakımından ne denli zorlandıkların göstermesidir.

Birlik Anlaşması, primer hukuk, birbirinden kesin olarak farklı ve heterojen karakterli düzenlemelerden oluşmaktadır. Birlik primer hukuku bir taraftan üç Topluluk anlaşmasının Birlik anlaşmasına enkorpere edilen değişiklik hükümlerini ( $\mathrm{AB}$ Anlaşması/Maastricht Anlaşması md.G - I; Maastricht Anlaşmasınn yürürlüğe girmesiyle primer Topluluk hukukunun ayrılmaz parçası olmuştur), diğer taraftan ODGP (AB Anlaşması/Maastricht md.J-J.11; $A B$ Anlaşması/Maastricht md.11-28) ve adalet ve içişlerinde işbirliği (AB Anlaşması/Maastricht md. K-K.9; AB Anlaşması/Amsterdam md.24-42) konusunda intergouvernemental hukukun temellerini içermektedir.

Primer hukukun bu birbirinden çok farklı alanlarının dengelenmesi ortak hükümlerden istisna düzenlemeleriyle ( $\mathrm{AB}$ Anlaşması/Maastricht md.A-F; $\mathrm{AB}$ Anlaşması/Amsterdam md.1-7) ve nihai hükümlerle ( $A B$ Anlaşması/Maastricht md.L-S; AB Anlaşması/ Amsterdam md.46-53) sağlanmaktadır. Bu istisna düzenlemeler sadece Birlik anlaşmasına taraf olan devletler bakımından değil, aynı zamanda üç Topluluk için de bağlayıcı sonuçlar doğurmaktadır. Bu sonuç AB Anlaşması madde $\mathrm{N}$ için de ayn şekilde, bu hüküm primer hukuka lafzen alınmaksızın da, AT primer hukukunun Birlik Anlaşmasıyla değiştirilmesi çerçevesinde zımnen geçerlidir. Birlik, AB Anlaşmasının $C$ maddesi 1.fıkrasına göre (AB Anlaşması/Amsterdam md.3, fikra 1) amaçlarına erişmek için mütecanis bir kurumsal çerçeveye sahiptir. 
Avrupa Birliği'nin kurumsal çerçevesine ilişkin bir anlaşma değişikliğinde, organ tasarruflarının sonuçları bakımından farklı bir tablo ortaya çıkmaktadır. Sınırlı yetki prensibi ışı̆ıında Topluluğun organları olan Konsey, Komisyon, Avrupa Parlamentosu, Adalet Divanı ve Sayıştay Topluluklar için tasarrufta bulunur. Organların tasarruflarınun sonuçları hukuk sujesi olan ve egemenlik yetkileri ile donatılmış olan Topluluklar için doğar. Buna karşılık intergouvernemental karakterli alanlara ilişkin organ tasarruflarının sonuçları, özellikle Konseyin tasarruflarının sonuçları, ODGP (Maastricht md.J-1.11; AB Anlaşması/Amsterdam md.11-28) ve Adalet ve içişleri (AB/Maastricht md.K-K.9; AB/Amsterdam md.29-42) alanlarında münhasıran Birlik devletleri bakımından doğmaktadır. Birliğin herhangi bir hukuk sujeliği bulunmamaktadır. Organ tasarruflarının sonuçları bakımından ortaya çıkan bu tablo, anlaşma değişikliği prosedürüne organların katılımı (AB Anlaşması md.N, fıkra 1; AB Anlaşması/Amsterdam md.48) bakımından da doğmaktadır.

Supranasyonal ve intergouvernemental Birlik primer hukuku arasındaki bu fark anlaşma değişikliğine ilişkin DH anlaşmalarının Birlik hukukundaki sonuçları bakımından da ortaya çıkmaktadır. Eğer anlaşma değişikliğine ilişkin $\mathrm{DH}$ anlaşmaları, $\mathrm{AB}$ Anlaşmasının $\mathrm{N}$ md. 1 fikrasını (AB Anlaşması/Amsterdam $48 \mathrm{md}$.) ihlal ediyorsa (şekli revizyon prosedürü) söz konusu değişiklik anlaşması, Topluluk Hukuk düzeninde ATAD tarafından denetlenen Topluluk Hukuk prosedürü çerçevesinde uygulanmaz. Buna karşılık Birlik anlaşmasına aykırı değişiklik anlaşması, intergouvernemental alana ilişkinse, Birlik devletleri bakımından istenilen sonuçları doğurur.

\section{Anlaşma Değişikliğinin Şekli ve Koşulları}

1. Birlik anlaşmasına göre, değişiklik prosedürü ve genel DH'na göre şekle bağlı olmayan anlaşma değişikliği:

$A B$ Anlaşmas1/Maastricht md. $N$ frkra 1'de öngörülen şekli revizyon prosedürü DH'na göre şekli olmayan prosedürden farklıdır. Multilateral anlaşmaların değişikliğine ilişkin olarak Viyana Anlaşmalar Hukuku Sözleşmesi (md.5,39 vd.) sadece bir dispositiv düzenleme içermektedir. Buna göre anlaşma tarafları daha önceden kararlaştırılmış olan değişikliğe ilişkin prosedürden, bu prosedüre uymaksızın aralarında uzlaşma ile her zaman kurtulabilirler. Genel Devletler Hukukuna göre her anlaşma, herhangi bir şekle bağl olmaksızın, değiştirilebilir (Verdross,A./Simma,B., Universelles Völkerrecht, 3.Aufl. 1984, S.792). Kurucu Anlaşmalar Hukuku bakımından şekle uymayan anlaşma değişikliklerinin sonuçları tartışmalıdır.

Mutabık olunan husus, Birlik Anlaşması'nın yahut Topluluk Anlaşmaları'nın değişikliğine ilişkin $\mathrm{N}$ maddesinden sapan her önlemin şekli revizyon hükmünün ihlali olarak kabul edilmesidir. $\mathrm{N}$ maddesinden sapma 
buna karşılık ilgili kurucu anlaşmanun spesifik bir düzenleme öngörmesi halinde mümkündür (Klein,E., bknz: Heilbronner, K./Klein,E./Magiera,S./MüllerGraff,P.-Ch., Handkommentar zum Vertrag über die Europaeische Union (EuV/EGV), Loseblatt (Stand:19914), Art.N Rz.7). Maastricht Anlaşmasınun madde N 1.fıkrasında öngörülen prosedürden sapmayı mümkün kılan AKÇT Anlaşmasının 95.md 3.fıkrası bu çerçevede iyi bir örnek oluşturmaktadır (küçük revizyon).

2. Genel Devletler Hukuku'na göre şekle uymayan anlaşma değişikliğinin caiz olması:

Bu çerçevede supranasyonal hukuk düzeninde ve intergouvernemental hukuk düzeninde anlaşmada öngörülen şekle uymayan anlaşma değişiklikleri konusu ele alınabilir. Hukuki niteliği tartışmalı olan Lüksemburg uzlaşısının (29.1.1966 tarihli bu uzlaşı tarım alanında nitelikli çoğunlukla karar alma konusundaki uyuşmazlığı çözmüştür. Fransa, boş sandalye politikası uygulayarak, Bakanlar Konseyi'ni bloke etmiş ve ağır bir krize neden olmuştur. Hakim olan görüşe göre Lüksemburg uzlaşısı, hukuki bağlayıclığı olmasa da, AET Anlaşmasının 43.madde 2.f1kra 3.bendini, AET Anlaşmasının 7.maddesi ile bağlantı içinde geçiş döneminin 2.aşamasından sonra bağlayıcı olarak öngörülen nitelikli çoğunlukla karar vermeye ilişkin düzenlemesini modifiye etmiştir) ve Iyonya uzlaşısının (İyonya uzlaşısı Lüksemburg uzlaşmasını yeniden canlandırmıştır. Önemli çıkarların söz konusu olması durumunda Finlandiya, Avusturya ve İsveç ile yapılan katılma anlaşmasında yer alan yeni baraj düzenlemesi (AT Anlaşması 148.madde, 2.fıkra) dikkate alınmaksızın, katılmadan önce geçerli olan azınlık oyu uygulamasına bir kararın alınmasını engelleyen oy olarak devam kararı verilmiştir) ortaya koyduğu üzere anlaşma tarafları $N$ maddesinde öngörülen düzenlemeyi dikkate almaksızın sorunlu konularda uzlaşma yapabilmektedir.

Üye devletlerin anlaşmaların efendisi olduğunu savunan görüş, anlaşmaların şekle uymaksızın değiştirilmesi olasılığını kabul etmektedir. Bu şekilde devletlerin egemen eşitliğine ilişkin Devletler Hukuku prensibi vurgulanmaktadır. Bu görüş, entegrasyon yanlısı bir yaklaşımı yansitmamaktadır. Bunun aksine Lüksemburg uzlaşması öncesi söz konusu olduğu üzere, ağır entegrasyon krizleri yaşamamak için, Kurucu anlaşmaların Devletler Hukuku niteliğinin altın çizen, Devletler Hukuku anlaşmalarının hukuki formlarının sadece dış görünüşle ilgili anlamsız birşey olmadığını, tersine Avrupa Toplulukları'nın hukuki varlığı için anlaşma taraflarının görüşlerinin ve iradelerinin uzlaşması gerektiğini ortaya koymaktadır (Tomuschat, Ch., bknz.: Bonner Kommentar zum Grundgesezt, Loseblatt (Stand: 1981). Art.24 Rz 48).

Birlik Hukuku'nun anlaşma taraflarını ne derece $A B$ Anlaşması/Maastricht $\mathrm{N}$ maddesi 1.fıkrasında öngörülen prosedüre tabi 
kılınabileceği bununla beraber tartı̧̧alıdır. Bu çıkmaz çerçevesinde hukuki niteliği tayin edilemeyen siyasi uzlaşmalar, Lüksemburg uzlaşması veya lyonya uzlaşması gibi çözümler gündeme gelmektedir. Devletler Hukuku'nun genel kurallarına göre devletler kendi aralarında yaptıkları bir Devletler Hukuku anlaşmasını mutabakatla herhangi bir şekle bağlı olmaksızın değiştirebilirler. $\mathrm{Bu}$ şekli olmayan anlaşma değişikliği anlaşma taraflarınun daha önce öngördükleri değişiklik prosedüründen kurtulma hakkını da beraberinde getirmektedir. $\mathrm{Bu}$ olasılık, $\mathrm{AB}$ anlaşmasınn $\mathrm{N}$ maddesi 1.fikrasında öngörüldüğü üzere değişiklik prosedürünün zorunlu bir karakter kazanması durumunda ortadan kalkmaktadır (Meng,W., bknz.: v.d. Groeben,H./ Thiesing, J./Ehlermann, C.-D. (Hrsg), Kommentar zum EWG-Vertrag, 4.Auflage, 1991, Art.236 Rz.27; Nikolaysen,G., Europarecht I, 1991, S.72 vd.). Öngörülen şekil böyle bir durumda anlaşma taraflarının takdirine bırakılmamaktadır. $A B$ Anlaşmasınun $N$ maddesi 1.fikrasında öngörülen prosedür Genel Devletler Hukuku'nun jus cogens karakterli bir normunun kodifikasyonu olarak görülemez. Zira bu düzenleme uluslararası camianın ne evrensel ne de bölgesel order public'i olarak görülebilir. Bu nedenle, anlaşma değişikliğine ilişkin bir şekli düzenleme, devletlerin bu çerçevedeki Devletler Hukuku yetkilerini kaybetmeleri koşuluyla jus cogens karakteri kazanabilir. Kurucu anlaşmaların, AB Anlaşmasınn $N$ maddesi 1.fikrası muvacehesinde değiştirilebileceğine ilişkin iradesini açık olarak ortaya koyması halinde bu durum söz konusu olabilirdi. Üye devletlerin egemenlik yetkilerini kaybetmesi, Birliğin devlet benzeri bir yapıya dönüşmesiyle mümkündür. Bu ise, üye devletlerin şu anda istemedikleri bir sonuçtur. Aralarında sağlayacakları bir uzlaşma ile yapabilecekleri anlaşma değişikliklerine ilişkin egemenlik hakkundan feragat iradesi, başka bir ifade ile üye devletlerin bu çerçevede kapsamlı bir entegrasyon adımı atmak istedikleri ne Birlik anlaşmasında ne de üyelerin tutumlarında saptanabilmektedir.

Alman Federal Anayasa Mahkemesi de, Maastricht Anlaşmasına ilişkin kararında Birliğin gelişmesini Birliğin demokratik dayanaklarının entegrasyonla uyum içinde gelişmesine ve entegrasyon çerçevesinde üye devletlerde canlı bir demokrasinin mevcudiyeti koşuluna bağlamaktadır (BVerf.GE 89, 155(213)). Anayasa mahkemesinin görüşüne göre Anayasa hukukunda öngörülen bu entegrasyon koşulu, ağır bir şekilde ihlal edildiği takdirde, Avrupa Entegrasyonu'na ilişkin Birlik anlaşması feshedilebilir. Anayasa Mahkemesi görüşü 1şı̆ıında, üye devletlerin Devletler Hukuku muvacehesinde bir opsiyonunun bulunduğunu, acil durumlarda krize bağlı olarak değişen durumlara uyum için mutabakatla, öngörülen şekli prosedürün dışınđa anlaşma değişikliği yapılabileceği söylenebilir. Ultima ratio başvurulabilecek bu durum, Kurucu Anlaşma'nın kendisinde AKÇT için olduğu gibi özel bir düzenleme bulunmadığı nispette Devletler Hukuku ışığında geçerli olmasına karşıllk, Topluluk Hukuku'nun bir ihlalini teşkil etmektedir. AB Anlaşması $\mathrm{N}$ maddesi o 
halde emredici bir Devletler Hukuku normu değildir. $N$ maddesinin kendisi de kendisi tarafından öngörülen prosedür ışığında değiştirilebilir. AB devlet benzeri bir statüye sahip değildir. AB kendi yetkilerini yaratamaz. AB'nin varlığı ve yetkileri kurucu devletlerden soyutlanmış değildir. Kurucu devletler, AB Anlaşmasının $\mathrm{N}$ maddesi 1.fikrasından sapan Devletler Hukuku anlaşmaları yapabilir. Bu anlaşmalar, Birlik Hukuku'na ve Topluluk Hukuku'na aykırı olmasına rağmen, böyle bir değişiklik anlaşması $\mathrm{N}$ maddesinin Devletler Hukuku ışığında emredici bir norm karakterine sahip olmaması nedeniyle, üye devletler arasında hukuki sonuç doğurur. Bu çerçevede ATAD'ın AET Anlaşmasının 228.madde 2.fıkrası ışı̆ında vermiş olduğu Avrupa Ekonomik A'lanı (EWR) hakkındaki danışma görüşünün (EuGH, Gutachten 1/91, Slg.1991, [-6079 vd.) ne şekilde anlaşılacağı tartışmalıdır. ATAD bu görüşünde bir ortaklık anlaşmasıyla Topluluk dayanaklarının zımnen değiştirilemeyeceğini dile getirmiştir. AT'ın 238.maddeye göre sahip olduğu anlaşma akdetme yetkisinin Avrupa Ekonomik Alanı için yargı sistemi yaratmaya esas olamayacağına, ATAD kararlarının AT'yi bağlayacağını, yargı yetkisi bakımından ATAD'ın 164.maddeye göre sahip olduğu münhasır ýetkinin Topluluğun dayanaklarından birisi olarak ihlal edilemeyeceğini dile getirmiştir. Bunun dışında ATAD'ın kararı, AT hukuk sisteminin, Kurucu anlaşmaların değiştirilemez hükümler içerdiği ve hatta AT Anlaşmasının 236.maddesinde öngörülen şekli prosedür ışığında dahi bú hükümlerin değiştirilemeyeceği şeklinde yorumlanmıştır. Ancak, ATAD'ın içtihat yoluyla anayasalarda olduğu gibi değiştirilemez anlaşma normu ýaratma yetkisi tartışılması mümkün bir konudur. ATAD'ın içtihadı sadece böyle bir değişiklik anlaşmasının Birlik ve Topluluk Hukuku'na aykırılığın saptanması ve bu anlaşmanın iç pazarda hüküm ve sonuç doğurmamasına ilişkin olup, anlaşmanın Devletler Hukuku alanundaki geçerliliğini etkileımez.

3. Öngörülen prosedüre uymayan anlaşma değişikliğinin Birlik Hukuku'ndaki sonuçları:

$A B$ anlaşmasının $N$ maddesi 1.fıkrasına uyulmaksızın gerçekleştirilen anlaşma değişikliği Devletler Hukuku bakımından geçerlidir; ancak Birlik anlaşmasına aykırıdır.

a. Anlaşmanın Topluluk Hukuk düzeninde etkileri

Bir Devletler Hukuku anlaşması, Avrupa Birliği Anlaşmasının N maddesine aykırı olarak AT Anlaşmasında yer alan prosedürü, yetkiyi yahut maddi hukuku değiştiren bir düzenleme içerdiği takdirde, Topluluk Hukuku'nun korunmasindan sorumlu olan ATAD Topluluk Hukuku'na aykirı değişikliği Devletler Hukuku bakımından geçerli olmasına rağmen uıgulamaz. Böyle bir anlaşma, AT Anlaşmasının 5.madde 1.fıkrası ve 2.fıkrası muvacehesinde (AT Anlaşması/Amsterdam md.10 fikra 1 ve 2) sadakat 
kuralının ihlalidir. Sadakat kuralının bu ihlali $\mathrm{N}$ maddesinin ihlali olarak ortaya çıkan Devletler Hukuku anlaşmasının Topluluk iç hukukunda uygulanmaması ile müeyyidelendirilir. $N$ maddesinde öngörülen prosedür 1 şığında ortaya ģkan değişiklik Topluluk iç hukukunda hüküm ve sonuç doğurur. Bu durum özellikle Birlik anlaşmasında yer alan "uyum prensibi" 1şığında (AB Anlaşması/ Maastricht madde C; $A B$ Anlaşması/Amsterdam madde 3) ve Birlik anlaşması tarafından açıķa varsayılan AT primer hukukunun zımni değişikliği çerçevesinde söz konusu olabilir. Maastricht Anlaşması ve Amsterdam Anlaşması, öngörülen prosedüre göre ortaya çıkmıştır. Anlaşma değişikliğine ilişkin hüküm sadece muayyen bir prosedüre uyulmasını öngörmektedir. Buna karşllık primer hukuk, metnin açk ve lafzen değiştirilmesini öngörmemektedir. AT primer hukukunun hiçbir hükmü de bunu talep etmemektedir.

Anlaşmada öngörülen prosedüre uymayan Devletler Hukuku anlaşmalarıyla yapilan değişikliklerin Topluluk Hukuku'nda hüküm ve sonuç doğurmaması, Topluluğun temel dayanaklarının bu değişiklikten etkilenmesine bağlı değildir. Temel dayanakların dışında kalan hususlarda informel anlaşma değişikliklerinin Topluluk Hukuku'nda hüküm ve sonuç doğurmasına izin verilmesi durumunda önemli bir hukuki güvensizlik probleminin yaşanılması kaçınılmazdır. ATAD'ın Avrupa Ekonomik Alanı'na ilişkin (EuGH, Guachten 1/91, Slg.1991, 1-6079 vd) kararının hiçbir şekilde Topluluk Hukuku'nun temel dayanaklarına ilişkin konularda informel anlaşma değişikliği yaplamaz şeklinde anlamak mümkün değildir. N maddesinde öngörülen prosedüre aykırı olarak gerçekleştirilen gerek lafzi gerek zımni primer hukuk değişikliklerinin Topluluk Hukuku'nda uygulanmaması ayn zamanda supranasyonel Topluluk Hukuku'nun demokratik meşruiyet dayanağını temin etmektedir. Üye devletler hukuk düzeninde doğrudan hüküm ve sonuç doğuran Topluluk hukuk düzeni demokratik meşruiyetini ulusal parlamentoların uygun bulma kanunları üzerinden temin etmek zorundadır. Sadece $\mathrm{N}$ maddesinde öngörülen prosedüre uygun olarak gerçekleştirilen anlaşma değişiklikleri ulusal parlamentolar bakımından onay kanunu çalışmaları çerçevesinde esas alınabilir. Primer Topluluk Hukuku'na ilişkin değişikliklerin ulusal uygun bulma kanunlarma yansimaması, Federal Alman Anayasa Mahkemesi'nin Maastricht kararında dile geldiği üzere, AT Anlaşmasının 235.maddesinin geniş yorumlanması ve dolaylı olarak anlaşmanın tamamlanması olur. Bu durum yetki normlarınn Topluluk organ ve kurumlanı tarafından kullanılırken, Birlik anlaşmasının sınırlı yetkinin kullanılması ile anlaşma değişikliği arasında ayrım yapıldığı ve yorumların bu nedenle sonuç olarak anlaşmaların genişletilmesine neden olamayacağ kuralın gündeme getirmektedir. Federal Alman Anayasa Mahkemesi yetki normlarınun bu tür yorumlarının Federal Almanya için hüküm ve sonuç doğurmayacağın kararında açıkça dile getirmiştir (BVerfGE 89,155). ATAD yetkisinin olmaması nedeniyle $N$ maddesi dışında gerçekleştirilen anlaşma değişikliklerinin ne geçerliliğini karara bağlayabilir ne de onları yorumlayabilir. ATAD, Komisyon 
tarafından açlan ihlal davası üzerinden (AT anlaşması/Maastricht 226) üye devletlerin informel anlaşma değişikliği nedeniyle ortaya çkan $\mathrm{N}$ maddesinin ihlalini saptayabilir. ATAD'ın bu çerçevedeki yetkisi md.L $c$ bendi (Maastricht/Avrupa Birliği Anlaşması; Amsterdam md.46 e bendi) ışığında N maddesinde öngörülen prosedürün ihlalinden doğmaktadır.

b. Ortak dış politika ve güvenlik; adalet ve içişleri alanında informel anlaşma değişikliği

$\mathrm{N}$ maddesinin 1.fikrasının ihlali sonucu doğan Devletler Hukuku anlaşmalarının Topluluk Hukuk düzeninde özellikle Komisyon ve ATAD tarafından denetlenen alanda uygulanmazken, bu tür değişiklik anlaşmalarınun intergouvernemental karakterli ortak dış politika-güvenlik ve adalet ve içişleri alanlarında birlik devletlerinin istediği sonuçları prensip olarak doğurması mümkündür. Ortak dış politika, güvenlik, adalet ve içişleri alanı üye devletler ve Topluluk ilişkilerinde sadakat prensibine tabi olmayıp, uluslararası ilişkilerin Devletler Hukuku struktur prensiplerine tabidir (örneğin lex posterior kurall, egemen eşitlik prensibi gibi). Bu şekilde $\mathrm{N}$ maddesi dışında meydana gelen bir Devletler Hukuku anlaşması Devletier Hukuku'na göre lex posterior kuralı ı§̧ı̆ında kabul edilebilir. Ancak, üye devletlerin bu derogation tasarrufu, Birlik anlaşmasına aykırıdır. Değişiklik konusu ortak dış politika-güvenlik politikası veya adalet ve içişleri alanına ilişkin olmakla beraber ATAD anlaşma ihlalini Maastricht anlaşması $\mathrm{L}$ maddesinin $\mathrm{c}$ bendi ışığında tespit etme yetkisine sahiptir. ATAD ortak dış politika-güvenlik ve adalet ve içişlerine ilişkin geçerli primer hukukun kapsaminn tayininde prensip olarak yetkisini kabul etmektedir. Bu durum özellikle adalet ve içişlerinden farklı olarak, ortak dış politika ve güvenlik alanında Amsterdam Anlaşmasında da ATAD'ın yetkisinin kabul edilmemesi nedeniyle problem yaratabilecektir.

Diğer bir özel problem ise lex posterior kuralının Birlik primer hukuku ve Birlik sekunder hukuku - ODPG ve adalet ve içişlerine ilişkin önlemler ilişkisinde de geçerli olup olmayacağıdır. Bu hukuki tasarruflar söz konusu sütunların intergouvernemental karaktere sahip olması nedeniyle Devletler Hukuku karakterlidir. Bu nedenle, prensip olarak primer hukukla ayni hiyerarşide görülmesi gerekmektedir. Ancak, Amsterdam Anlaşması adalet ve içişleri alanında kararlaştırılan hukuki tasarruflar bakımından yeni 35 . maddesi ile intergouvernemental Birlik primer hukukunun Birlik sekunder hukukuna nazaran önceliğini vurgulamaktadır. Amsterdam Anlaşmasının 35. maddesine göre ATAD adalet ve içişleri alaninda ulusal mahkemelerin ön karar başvurularına (fikra 1-3), üye devletlerin ve Komisyonun 34. madde 2. fikra (Amsterdam Anlaşması) ışığında açtığı davaya ve icra önlemlerine ilişkin iptal davalarına (fıkra 6) bakmak ve bu tasarrufları yorumlamak ve geçerliliğini karara bağlamak yetkisine sahiptir. Amsterdam Anlaşmasının 35. madde 6. fikrası Birlik primer hukukunda yer alan iptal sebeplerini intergouvernemental 
Birlik sekunder hukuku bakımından AT Anlaşmasının 173. madde 2. fikrasında (Amsterdam Anlaşması md.230, 2. fıkra) yetkisizlik, önemli şekli şartların ihlali, bu anlaşmanın ihlali yahut anlaşmanın uygulanmasına ilişkin bir normun ihlali veya takdir yetkisinin kötüye kullanulması olarak saymaktadır. Birlik sekunder hukukunun bu şekilde geçersiz olarak saptanması, AT Anlaşmasının 174.madde 1. fikrasına benzer bir hüküm bu çerçevede yer almamakla beraber (AT Anlaşmasi/Amsterdam md.231 fikra 1) ilgili tasarrufun geçersiz ilan edilmesi sonucunu doğuracaktır. Bu prosedür adalet ve içişlerinde işbirliğine ilişkin sekunder hukuk tasarrufları ile sınırlıdır. ATAD'ın ortak dış ve güvenlik politikası alanunda Amsterdam anlaşmasıyla da herhangi bir yetkisi kabul edilmemiştir. Hukuk dogmatiği kaynaklan, ortak dış ve güvenlik politikası alanundaki organ yetkileri ve prosedür benzerliği nedenleriyle intergouvernemental karakterli adalet ve içişleri alanundaki primer ve sekunder hukuk alanındaki hiyerarşik ilişkinin her iki alan bakımından aynı olması gerektiğini vurgulamaktadır.

Birlik primer hukukunun Birlik sekunder hukukuna nazaran önceliğinin, sekunder hukukun da bu alanda Devletler Hukuku karakterli olması nedeniyle lex posterior kuralı ışığında irdelenmesini gerektirmektedir. Birlik devletlerinin Devletler Hukuku çerçevesindeki şekillendirme yetkilerini sınurlamaları, Birlik anlaşmasının bir Devletler Hukuku anlaşması olarak korse etkisinden doğmaktadır. Birlik anlaşması ile Birlik devletleri kendileri bakımından hukuki bir çerçeve saptamıştır ve bu çerçeveye uyma bakımından kendilerini taahhüt altına sokmuşlardır. Primer hukukta ortaya çıkan bu korseden sekunder hukukla aşılması geçersizlik müeyyidisine tabidir. Bu şekilde lex posterior ilişkisi primer hukuk ve sekunder hukuk ilişkisinde söz konusu değildir.

Birlik devletleri ortak dış ve güvenlik politikası, adalet ve içişlerinde işbirliği alanunda da kendi egemen iradeleriyle sekunder hukuk tasarruflarıla primer hukuku lex posterior kuralı ışı̆ında değiştirmekten vazgeçmiştir. Primer hukuku değiştiren sekunder hukuk geçersizdir. Birlik primer hukukunun Birlik sekunder hukukuna nazaran önceliği Amsterdam Anlaşmasının 35.maddesi ışığında gerçekleştirilebilecek geçerlilik denetimi ile güçlendirilmiştir. Ancak bu çerçevede söz konusu tasarrufun informel bir primer hukuk değişikliği teşkil edip etmediği önem kazanmaktadır. Birlik primer hukuku ile bağdaşmayan Birlik sekunder hukukunun informel primer hukuk değişikliği olarak yorumlanarak etkinlik kazanmasinn bir tehlike olarak gözönünde bulundurulması gerekmektedir. Birlik devletleri, Birlik primer ve Birlik sekunder hukuk ilişkisinde bağlayıcı şekilde Devletler Hukuku çerçevesinde sahip oldukları düzenleme serbestisinden feragat etmişlerdir. 
c. Anlaşma değişikliklerinin üye devletlerin hukuk düzeninde etki doğurması

$\mathrm{N}$ maddesine aykırı olarak gerçekleştirilen anlaşmaların geçerliliğinin intergouvernemental karakterli ortak dış ve güvenlik politikası, adalet ve içişlerinde işbirliği alanları ile sınurlı tutulması nedeniyle bu anlaşma değişikliklerinin ulusal alanda etkisi söz konusu değildir. Birlik anlaşmasına ters düşen anlaşmaların Kurucu anlaşmanın doğrudan etki doğuran Topluluk Hukuku'na ilişkin olması durumunda Topluluk Hukuku'nun önceliği prensibi işlemektedir. Topluluk Hukuku değişikliğe uğramamıs formu içinde, Birlik anlaşmasına ters düşen Devletler Hukuku anlaşmasına nazaran önceliğe sahiptir. Ulusal organlar Birlik hukukuna aykın anlaşmayı değil, Birlik Hukuku'nu uygulamak durumundadir. Ulusal mahkemeler, Birlik hukukuna aykırı Devletler Hukuku anlaşmaların ATAD'a yorum ve geçerlilik denetimi için arzedemez. Zira bu anlaşmalar Topluluk Hukuku'nun bir parçası değildir. Bu anlaşmalar, Birlik anlaşmasına aykırı, ancak Devletler Hukuku'na göre lex posterior kuralına nazaran geçerlidir.

4. $\mathrm{N}$ maddesinde yer alan prosedürün $\mathrm{N}$ maddesi için işletilmesi:

Birlik devletleri Birlik anlaşmasının $\mathrm{N}$ maddesini değiştirme yetkisine sahiptir. Böyle bir değişiklik, Konsey, Komisyon ve Avrupa Parlamentosu'nun katılacağı bir prosedürle gerçekleşebilir. $N$ maddesinin 1.fikrasının değiştirilmesi bir uluslararası kuruluşun kurucu anlaşmasının geleneksel Devletler Hukuku kurallarıyla değiştirilmesi prosedürüne tabidir. Avrupa Birliği bu çerçevede özel bir organa sahip olmadığ 1 gibi, $N$ maddesi Birlik hukuk düzeninin değiştirilemez hükümlerini de içermemektedir. ATAD'ın Avrupa Ekonomik Alanı'na ilişkin birinci görüşü ışığında Kurucu anlaşmaların mutlak değişikliğe kapalı hükümlerinden, örneğin Topluluk Hukukunu koruma sisteminden söz etmesi, sadece Avrupa Birliği'nin yargı̨̧ hukuku üzerinden devlet benzeri, Kurucu devletlerin iradesinden bağımsız bir yapıya dönüşmesini engelleme iradesini ortaya koyma amacina matuftur.

Ortak dış politika ve güvenlik veya adalet ve içişlerinde işbirliği alanlarında Birlik hukukunun intergouvernemental hükümlerinin Birlik hukukuna aykırı olmakla beraber informel değiştirilmesi geçerli kabul edilirken, $N$ maddesinin informel değişikliği aynı etkiyi doğurmamaktadır. Aksi takdirde AB'nin tüm yapısı, primer seviyedeki Topluluk Hukuk düzeni, anlaşma taraflarının keyfi tasarrufuna bırakılmıs olurdu. $\mathrm{N}$ maddesinin şeklen değiştirilmemesi durumunda informel anlaşmaların Genel Devletler Hukuku muvacehesinde Birlik iç hukuk düzeninde sınırsız etkiye sahip olması mümkündür. Ancak, AB/Maastricht Anlaşmasınun A maddesi a fikrasında ( $A B$ Anlaşması/Amsterdam madde 2 fikra 2) daima daha sıkı bir Birliğin gerçekleşmesinde yeni bir aşama olarak Birlik devletleri Genel Devletler 
Hukuku'nun lex posterior kuralına istinaden Birlik anlaşmasınun korse etkisini, öngörülen prosedüre riayet etmeksizin ortadan kaldırmaktan vazgeçmişlerdir. AB'nin yapısı, entegrasyon hukukunun korse etkisinin dokunulmazlığına istinat etmektedir. $A B$ entegrasyonu yeni aşamasına Birliğin üye devletlerin Devletler Hukuku'na istinat eden ad hoc iradesine, informel lex posterior düzenlemesine bırakılmaması durumunda erişecektir. Tabii ki $\mathrm{N}$ maddesinin, $\mathrm{N}$ maddesinde öngörülen prosedür çerçevesinde değiştirilmesi mümkündür. Bu durum örneğin Federal Alman Anayasası'nın 79. maddesi 3 fıkrasının süreklilik karakterinden farklı bir tablo oluşturmaktadır. 79 madde 3.fikra şekli anayasa değişikliği ile dahi değiştirilemez bir maddedir.

5. Anlaşmaların değiştirilmesi prosedürü:

Bir anlaşma değişikliğinin (AB Anlaşması/Maastricht) $\mathrm{N}$ maddesine göre meydana gelebilmesi için:

- Üye devletlerden birinin hükümetinin veya Komisyonun değişiklik tasarısı getirmesi;

- Konsey'in, Avrupa Parlamentosunun ve Komisyonun, Merkez Bankasının dinlenmesinden sonra hükümetler arası bir konferans için görüş bildirmesi;

- Bu hükümetler arası konferansta kararlaştırılan değişikliklerin tüm üye devletlerin anayasa hükümlerine göre onaylanması;

- Tüm üye devletlerin onay belgelerini İtalyan hükümeti nezdinde depo etmesi.

Prosedür bir üye devlet hükümetinin veya Komisyon'un değişiklik tasarısı sunmasıyla başlamaktadır. Sadece hükümetler ve Komisyon anlaşma değişikliği konusunda inisiyatife sahiptir. Uygulamada Avrupa Parlamentosu ve Konsey, anlaşma değişikliği bakımından siyasi dürtüler yapabilir.

Şüphesiz prosedürün şeklen inisyatif hakkına sahip olanlar tarafından başlatılması gerekir. Konseye bir tasarı geldiği zaman önce Avrupa Parlamentosu'nun, tasarının bir devletten gelmesi halinde söz konusu devletin ve Komisyon'un dinlenmesi gerekmektedir. Değişiklik tasarısı para birliğinin kuramsal özellikleri ile bağlantılı olması halinde Avrupa Merkez Bankası'nın dinlenmesi gerekmektedir. Parlamentonun, Komisyonun yahut Avrupa Merkez Bankası'nun bu çerçevede olumsuz bir görüş bildirmesi durumunda Konsey'in başvuru hakkında mutlak bir şekilde olumsuz bir karar vermesi sonucu doğmamaktadır. Önemli olan Konsey'in karar esnasında dikkate almasını teminen organların görüşlerini bildirme olanağının sağlanmasıdır. Organlardan birinin görüş bildirmekten çekinmesi durumunda Konsey, prosedüre devam etmeden, söz konusu organın görüşünü bildirmesi için gayretini esirgeyemez. 
Konsey organların görüşünü aldıktan sonra hükümetler arası bir konferansın toplanıp toplanmaması konusundaki görüşünü oluşturur. Konferansın toplanmaması görüşü prosedürü sona erdirir. Konferansın toplanmasına ilişkin görüş oluşması halinde, Konferans toplantıya davet edilir. Konsey bu kararı basit çoğunlukla alır. Bu karar, Konferans'ın davet edilmesi bakımından, Konsey başkanın mükellef kılar. Üye devletlerin hükümet temsilcilerinin katıldığı revizyon konferansinun görevi, intergouvernemental görüşmeler çerçevesinde yapılacak anlaşma değişikliklerini içerik olarak kararlaşturmak ve oylamaktır. Üye devletler Konsey'in kararı ile bağlı değildir. Şayet Konsey'in kararından saparlarsa, dinlenilmesi gereken organlar yeniden dinlenir. Bu yeniden dinlenme uygulamada üye devletler ve organlar arasinda, örneğin Daimi Temsilciler Komitesi üzerinden sağlanmaktadır.

Anlaşma değişikliği prosedürü hem üye devletlerin hem de Konsey, Komisyon, Avrupa Parlamentosu'nun protokole katılmasını öngörmektedir. Birliğin istinat ettiği anlaşmalar bir taraftan intergouvernemental karakterli hükümler (ortak dış politika-güvenlik politikası ve adalet ve içişlerinde işbirliği) diğer taraftan AET, AKÇT, AAET kurucu anlaşmaları bakımından supranasyonal karakterli hükümler içermektedir. Bu durum özellikle $\mathrm{N}$ maddesi çerçevesinde gerçekleştirilen anlaşma değişikliğine ilişkin prosedürde organ tasarruflarının kime atfedileceği hususunu da gündeme getirmektedir.

Ortak dış ve güvenlik politikası ve adalet ve içişlerinde işbirliği alanlarındaki intergouvernemental hükümlerin değiştirilmesi çerçevesinde organ tasarrufları birlik devletlerine atfedilmektedir. Topluluk anlaşmaları değişikliklerinin söz konusu olması durumunda buna karşılık Konsey, Komisyon ve Parlamento Topluluk organ olarak tasarrufta bulunmaktadir. Bir anlaşma değişikliği ile hem ortak dış ve güvenlik politikasının, hem de adalet ve içişlerinde işbirliğine ilişkin hükümlerin ve Topluluk anlaşmalarının hükümlerinin değişikliği söz konusu olduğu takdirde, söz konusu organlar bir taraftan Topluluk kurumları olarak, diğer taraftan üye devletlerin organları olarak tasarrufta bulunmuş kabul edilirler.

Konsey, Komisyon ve Parlamento'nun bu çifte fonksiyonu, Birlik anlaşmasının AT, AKÇT ve AAET anlaşmalarının anlaşmaların değişikliğine ilişkin hükümlerini kaldırması ve bu konudaki yegane düzenleme olarak anlaşmanın $\mathrm{N}$ maddesini kabul etmesinden ileri gelmektedir. Bununla beraber tasarrufların kime atfedileceği konusunda bir değişiklik yapılmamıştır (Koenig, Ch. Haratsch, A., Einführung in das Europarecht, 1996, S.211).

Anlaşma değişiklikleri bütün üye devletlerin bu değişiklikleri anayasalarındaki hükümlere göre onaylamasından sonra yürürlüğe girer. Primer hukukun geliştirilmesi veya değiştirilmesi bütün üye devletlerin parlamentolarınn uygun bulmasına bağlıdır. $\mathrm{N}$ maddesinin üye devletlerin 
anayasalanna atıf yapması, sadece Devletler Hukuku anlaşmalan bakımından genel olarak öngörülen anlama sahip olmayıp, ATAD tarafından denetlenen Birlik hukuku bakımından geçerlilik koşuludur; değişiklik anlaşmalarının Topluluk Hukuku'ndaki bağlayıcllğgı üye devletlerin tümünün bu değişikliği anayasaları ışığında onaylamasına bağlıdır.

Maastricht Anlaşmasının $\mathrm{N}$ maddesinin 1.fikra 3.bendinin ( $\mathrm{BB}$ Anlaşması/ Amsterdam md.48, 3.bend) üye devletlerin anayasa hükümlerine atıfta bulunarak, değişikliğin anayasalar ışığında onaylanmasının Birlik iç hukuku bakımından inşai etkisinin kabul edilmesi, Viyana Anlaşmalar Hukuku Sözleşmesi'nin 27 ve 46. maddelerinden sapmaktadır. Genel Devletler Hukuku'na göre ulusal hukukun ihlali Devletler Hukuku yükümlülüklerinin yürürlüğe girmesi bakımından prensip olarak dikkate alınmaz. Sadece ulusal anayasanun açı olarak ihlali bir öneme sahiptir. Viyana Anlaşmalar Hukuku Sözleşmesi'nin 46.maddesine göre böyle bir durumda anlaşmaya taraf devlet akdedilen anlaşmadan çekilmek bakımından bir olanağa sahiptir. Maastricht Anlaşmasınun $\mathrm{N}$ maddesinin 1.fikra 3.bendinin Viyana Anlaşmalar Hukuku Sözleşmesi'nin 27 ve 46.maddelerini, ulusal anayasaya göre onaylamayı inşai bir geçerlilik koşulu kabul etmesi sonucu, üye devletler arasında $\mathrm{N}$ maddesinde öngörülen prosedüre uymaksızın yapılan anlaşma değişikliği anlaşmalarının Topluluk Hukuk düzeninde uygulanması olanağını reddederek devre dışı bırakmaktadır. Buna göre onay hükümlerinin ihlal edilmesi anlaşma değişikliğinin Topluluk hukuk düzeninde hüküm ve sonuç doğurmamasına neden olmaktadır. Buna karşlik intergouvernemental karakterli alanlarda anayasaya aykırı olarak yapılan değişiklik anlaşmaları Devletler Hukuku'na göre prensip olarak etki doğurmaktadır. Zira, bu alanlar uluslararası ilişkiler düzeninin Devletler Hukuku struktur prensiplerine tabidir. Bu şekilde üye devletlerin anayasalarının onay hükümlerini $\mathrm{N}$ maddesi ışığında ihlal eden değişiklik anlaşmaları, Devletler Hukuku bakımından, intergouvernemental alanlarda lex posterior etkiye sahiptir. Bu çerçevede, Viyana Anlaşmalar Hukuku Sözleşmesi'nin 27 ve 46.maddeleri geçerliliğe sahiptir. Üye devletlerin anayasalarındaki onay hükümlerinin ihlali, $\mathrm{N}$ maddesine göre, Birlik anlaşmasının ihlalidir. $\mathrm{N}$ maddesinin dikkate alınmaması sonucu doğan bu ihlal, ortak dıs ve güvenlik politikası ve adalet ve içişlerinde işbirliği alanlarına ilişkin olsa da, ATAD bu anlaşma ihlallerini saptama yetkisine sahiptir.

Viyana Anlaşmalar Hukuku Sözleşmesinden sapan ulusal anayasa hükümlerine riayet edilmesini değişiklik anlaşmalarının Topluluk Hukuku'nda etkin olma koşulu olarak öngören Maastricht Anlaşmasının $\mathrm{N}$ maddesinde yer alan bu özel düzenleme, Devletler Hukuku'na ve ulusal anayasa hukukuna göre mümkündür. Ulusal parlamentoların $N$ maddesi ışı̆̆ında onay prosedürü çerçevesinde mekanizmaya dahil edilmesi, Topluluk egemenlik tasarruflarına demokratik meşruiyet temini bakımından önemli bir araçtır (BVerfGE 89,155). 
Üye devletlerin supranasyonal hukukla bağlliı̆ına demokratik meşruiyet kazandırılması (anlaşma değişikliklerinde) ulusal parlamentoların devreye girmesi ile sağlanmaktadır.

Değişikliklerin anayasa hükümlerine göre uygun bulunmasından sonra üye devletlerin yetkili organları onay tasarrufunu gerçekleştirir. Onay belgelerinin İtalyan hükümeti nezdine $\mathrm{AB}$ depoziteri olarak gönderilmesi gerekmektedir ( $A B$ Anlaşması/ Maastricht md. R; $A B$ Anlaşması/ Amsterdam md. 52).

\section{Sonuç:}

$N$ maddesinde öngörülen revizyon düzenlemesine aykırı olarak gerçekleştirilen, Devletler Hukuku'na istinat eden Topluluk anlaşmalarına ilişkin anlaşma değişiklikleri Topluluk Hukuk düzeninde özellikle Komisyon ve ATAD tarafindan denetlenen Topluluk Hukuk alaninda uygulanmaz. Buna karşıllk Birlik devletlerince istenilen, Birlik anlaşmasına aykırı değişiklik anlaşmaları intergouvernemental karakterli alanlarda lex posterior kuralına göre etki doğururlar. Üye devletlerin bu derogation tasarrufu Birlik anlaşmasına uygun, ancak Birlik hukukuna aykırıdır. Birlik sekunder hukuku buna karşıllk Birlik primer hukukuna tabidir.

ATAD N maddesinin ihlali sonucu yapılan anlaşmaların Topluluk Hukuku'nu ihlal ettiğini saptama yetkisine sahiptir. Aynı durum intergouvernemental karakterli anlaşmalara ilişkin anlaşma değişiklikleri bakımından da geçerlidir. ATAD Birlik anlaşmasının ihlal edilip edilmediğini saptayabilir.

$\mathrm{N}$ maddesinin üye devletlerin anayasasına atıfta bulunması, ATAD'a anlaşma değişikliği çerçevesinde söz konusu inşai geçerlilik koşulunu denetleme yetkisini vermektedir. $\mathrm{N}$ maddesinin kendisi de, içeriğinde öngörülen değişiklik prosedürü üzerinden değiştirilebilir. Buna karşılık $N$ maddesinin öngörülen prosedür dışında değiştirilmesi mümkün değildir. 
